\title{
LAS POBLACIONES RURALES DE MÉRIDA Y SUS RELACIONES INTERÉTNICAS CON ESTA CIUDAD CAPITAL DE LA ENTIDAD YUCATECA DE MÉXICO
}

\author{
Manuel Jesús Pinkus Rendón \\ mpinkus@uady.mx \\ Jorge Pacheco Castro \\ pcastro@uady.mx \\ José Antonio Lugo Pérez \\ lperez@uady.mx
}

Centro de Investigaciones Regionales Unidad de Ciencias Sociales Universidad Autónoma de Yucatán México

\begin{abstract}
RESUMEN
El objetivo de este trabajo es plantear algunas reflexiones sobre las relaciones que establecen las 47 comunidades rurales comisarías del municipio de Mérida, en el contexto de su convivencia cotidiana con esta ciudad y de los procesos de la economía liberal, por medio de los cuales se propicia la expansión de inéditas relaciones económicas, nuevos estilos de vida y valores sociales, y con ellos la propagación de la cultura occidental. En esencia, nos ocuparemos de destacar los vínculos interétnicos que establecen estos pueblos con su cabecera municipal, resaltando el lugar y el sentido de identidad que representan dentro de su actual estructura social.
\end{abstract}

Palabras clave: relaciones interétnicas, población rural y urbana. 


\section{ABSTRACT}

The aim of this paper is to propose some reflections on the relationships they establish the 47 rural communities in the municipality of Merida, in the context of their daily contact with the city and the liberal economic processes, through which fosters unprecedented expansion of economic relations, new lifestyles and social values, and with them the spread of occidental culture. In essence, we will highlight the inter ethnic ties which provide these villages with the main towns, highlighting the place and sense of identity that represented within its current social structure.

Keywords: inter ethnic relations, urban and rural population. 


\section{INTRODUCCIÓN}

El objetivo de este trabajo es plantear algunas reflexiones sobre las relaciones socioeconómicas y culturales que establecen las 47 comunidades rurales del municipio de Mérida, denominadas comisarías y subcomisarías, con esta ciudad que es su capital, como también de la entidad yucateca, en el contexto de su convivencia cotidiana con sus habitantes urbanos. De igual manera, nos interesa dar cuenta de los impactos que en estas sociedades han ejercido los procesos de la política económica neoliberal, cuyo mayor impulso lo recibiera del gobierno mexicano desde principios de la década de 1980 hasta los presentes días, para demostrar las condiciones estructurales mediante las cuales se han expandido en estas poblaciones, en el ámbito local, las relaciones económicas y socioculturales macro estructurales, inéditas, nuevos estilos de vida y valores sociales que hoy propaga la cultura occidental dominante en el orbe.

En esencia, nos ocupamos de destacar la naturaleza de las vinculaciones interétnicas que establecen estos pueblos con su cabecera municipal, resaltando el lugar y el sentido de identidad que representan dentro de la actual estructura social de la que forman parte, así como los cambios y persistencias que han ocurrido en los aspectos socioculturales de su vida, como efecto de los procesos macroeconómicos y modos estandarizados de vida que expande la cultura global sobre las sociedades nacionales en vías de desarrollo o en las denominadas subdesarrolladas de nuestras sociedades latinoamericanas.

Para el caso que nos ocupa en este trabajo, partimos del supuesto básico de que los problemas de pobreza y marginación económica, social, política y cultural que han caracterizado la condiciones de vida y las relaciones sociales de los pueblos denominados indígenas mayas yucatecos, son resultado del contexto histórico de su devenir y de las trasformaciones estructurales que el Estado contemporáneo ha impuesto en ellas, sobre todo desde que hiciera suyo el impulso de la política económica neoliberal, basada en libre mercado que ha sido inmanente a la globalización económica, impuesta por los gobiernos 
de los países poderosos y los grupos hegemónicos a las sociedades menos desarrolladas en una diversidad cultural y medio ambiental.

De cualquier modo es necesario enfatizar que la globalización económica y el imperio del mercado, se trata de macro procesos que, como bien señala Wolf, han tenido lugar en el orbe desde el desarrollo del sistema capitalista y de su «penetración», en la medida en que ha sido un sistema estructural que significó la repartición del papel que a cada nación le correspondería desempeñar dentro del orden económico mundial, basada en la expansión del capitalismo expresado en el desarrollo industrial y en la división internacional del trabajo, lo que implicaría desde entonces el predominio de unas poblaciones sobre otras.

Desde esta perspectiva, afirmamos que el concepto de pueblos indios, así como las características estigmatizadoras que se les ha construido y se continúa socializando a estos grupos socioculturales yucatecos para definirlos e interiorizarles una identidad ajena, en confrontación con la identidad occidental, urbana, desarrollada y moderna; en definitiva, no constituyen, por naturaleza u origen racial, propiedades definitorias de las condiciones depauperadas y marginadas en las que durante décadas siguen viviendo estos pueblos ni mucho menos son inmanentes a sus culturas ni a su forma de ser y concebir el mundo que los rodea, como tampoco pueden continuar siendo fundamento de las políticas asistencialistas o paternalistas con las que hoy se pretende, en algunos cosos, proteger y preservar o, en otros casos, utilizar como clientelismo político maleable durante los periodos de campañas electorales.

Visto desde estas perspectivas, por el contrario, planteamos que la categoría social de pueblos indios únicamente representa constructos ideológicos configurados tanto por las clases hegemónicas, como también por los pensadores de las ciencias sociales de determinadas corrientes, los cuales les han servido de fundamento para legitimar, a unos, las acciones expoliadoras que realizaban sobre los pueblos originarios, y, a los otros, las construcciones epistemológicas sobre la evolución, desarrollo y los cambios culturales que 
han experimentado los diversos grupos humanos de estos pueblos, respectivamente (Pacheco 2005: 43-69). Por lo tanto, la categoría de pueblos indios no constituye por reflexión erudita fundamento de las concepciones y percepciones que los pueblos se forjan sobre sí mismos, ni mucho menos para definirse e identificarse como parte de una cultura particular, sino tan sólo constituyen explicaciones ideológicas ajenas que les han sido impuestas para ejercer control sobre sus personas y sus recursos naturales, sus familias y comunidades enteras.

Desde esta perspectiva los conceptos de indígenas o pueblos indios, como hoy se les categorizan bajo el argumento de gestionar recursos económicos para canalizarles, por cierto escasos, o para propugnar la construcción de leyes que permitan su preservación, bajo las mismas condiciones estructurales, o tal vez mejores pero de todas maneras marginales a las sociedades modernas o urbanas, no pueden ser considerados como argumentos válidos para fundamentar la falta de participación y acceso de estas sociedades a los procesos de desarrollo y modernización de la sociedad más amplia. Por el contrario, se puede afirmar que, a lo largo de su historia, estas sociedades han tenido una intervención activa y de suma importancia en la construcción de las sociedades desarrolladas y del sistema que hoy las mantiene, y que en lo que no han participado ha sido, evidentemente, en la redistribución equitativa y justa de los recursos, de las riquezas generadas a partir de la explotación de la que han sido objeto por los grupos de poder, a través de las distintas épocas. Menos aún han sido sujetos de los supuestos «beneficios» del nuevo desarrollo económico del México contemporáneo ni de los nuevos procesos modernizadores que lo han acompañado y que lo vincula a la economía global y a los vertiginosos avances tecnológicos que ha experimentado el mundo global.

Desde esta perspectiva, en este trabajo se plantea el examen de la problemática, desde un esquema teórico metodológico, cuyos objetivos van más allá de la sola demostración de las formas de subyugación que ejercen los países centrales, representantes del sistema 
capitalista, sobre sus colonias, la periferia, para revelar también las respuestas de estas culturas frente a aquéllos:

...las reacciones de las micro poblaciones que habitualmente estudian los antropólogos, la gama y variedad de tales poblaciones, de sus modos de existencia antes de la expansión europea y del advenimiento del capitalismo y la manera en que estos pueblos fueron penetrados, subordinados, destruidos o absorbidos, primeramente, por el creciente mercado, luego por el capitalismo industrial... (Wolf 1987: 39).

En el marco de la nueva era de expansión del sistema capitalista en el orbe, basada en la economía del mercado global y el neoliberalismo económico de todas las naciones, las relaciones sociales de producción, la división social del trabajo, así como la distribución inequitativa de los recursos no han cambiado sustancialmente. Por el contrario, la globalización del mercado ha profundizado la polarización social, el monopolio de los recursos económicos y ha seguido la tendencia de la mayor concentración de los dineros en manos de las clases hegemónicas, en tanto la precarización de las condiciones de vida de las clases desposeídas se sigue recrudeciendo y expandiendo hasta otros sectores de la estructura social mexicana.

Desde luego, los aspectos sociales, culturales, políticos y medio ambientales de estos pueblos no han sido ajenos a estos procesos, en la medida en que la infiltración de los elementos de la cultura occidental y sus avances de expansión hegemónica han fluido con mayor rapidez hacia todos los rincones del planeta, favorecido todo ello por el impulso de la tecnología de la informática y de su aplicación a la movilidad de los capitales; de hecho estos son los objetivos sobre los que los países poderosos desean extender sus dominios y el ejercicio de su máxima extracción. Pero, asimismo, las culturas particulares de las sociedades nacionales, regionales y locales de los países en vías de desarrollo, tampoco se han quedado estáticas y han tenido que responder a los impactos de los procesos globales, algunas veces adaptándose y otras trasformándose, más, de cualquier modo, siempre 
luchando por salvaguardar los elementos simbólicos de la cultura y de sus recursos que les otorga su sentido de identidad y su patrimonio ancestral.

Cabe enfatizar que ante los procesos de la cultura global las culturas particulares denominadas como tradicionales, étnicas o periféricas, también plantean sus estrategias de supervivencia, no solo económicas y sociales, sino también políticas y culturales. En este sentido, se puede afirmar que, como bien nos señala Gilberto Giménez,

...la tradición y la modernización sólo se oponen como tipos ideales polares, pero históricamente no son totalmente incompatibles y excluyentes. No sólo pueden entremezclarse y coexistir, sino reforzase recíprocamente. Lo nuevo frecuentemente se mezcla con lo antiguo y la tradición puede incorporarse y adaptarse a la nueva sociedad emergente... (Giménez 1994: 158).

En este sentido, podemos afirmar que incluso en el marco de la economía neoliberal la tradición puede servir, y así debemos entenderla porque su persistencia lo testifica,

...como instrumento de crítica de la modernidad occidental, revelando por contraste modos de vida y de organización social menos individualistas, menos ferozmente competitivos, menos depredadores de los recursos naturales, y, sobre todo, menos contaminantes del entorno ecológico (Giménez 1994: $150)$.

La información con la que fundamentamos estas aseveraciones la recopilamos durante una investigación a partir de la cual realizamos un diagnóstico antropológico de los impactos del huracán Isidoro, en 2002, en las 47 poblaciones rurales que forman parte de la jurisdicción político administrativa del municipio de Mérida. Con esta finalidad levantamos 500 cuestionarios en igual número de familias de estos poblados emeritenses y a partir de éstos, de las entrevistas e historias de vida y de las observaciones realizadas en el contexto social, obtuvimos la información que nos permitió conocer y explicar, además de los efectos del huracán Isidoro en la economía de estas sociedades, los estrechos vínculos que sus habitantes mantienen con la ciudad y, sobre todo, las características relacionales que 
enmarca los vínculos sociales entre los habitantes de estas poblaciones con los citadinos. Por lo tanto, en este trabajo también damos cuenta acerca de cómo estas sociedades rurales de Mérida se perciben dentro del contexto de sus relaciones con su cabecera municipal, la cual ha sido beneficiada y la mejor favorecida de las políticas e inversiones públicas que se canalizan, principalmente, a los sectores empresarial y comercial, a quienes se les apoya primordialmente para participar en las relaciones del mercado global y de sus supuestos beneficios.

\section{LAS COMUNIDADES RURALES DE MÉRIDA Y EL CONTEXTO HISTÓRICO ESTRUCTURAL}

Las 11 comisarías y 36 subcomisarías del municipio de Mérida son pequeñas comunidades rurales ubicadas alrededor de esta ciudad y se encuentran bajo la administración del gobierno municipal de Mérida. En conjunto, estos poblados constituyen el área rural y algunos se encuentran ya conurbados con esta ciudad capital, en la medida en que se hallan a escasos kilómetros de ella e incluso algunos de estos pequeños poblados han sido absorbidos por la ciudad dada la expansión de la mancha urbana.

De acuerdo con el XII Censo de Población y Vivienda (Inegi 2000), en estas poblaciones viven 39,255 habitantes y hasta hace dos décadas la reproducción de las familias que en ellas habitan se fincaba, en gran medida, en una economía de subsistencia, caracterizada por el cultivo de la milpa, hortalizas, cría de animales de traspatio y cultivo de diversos frutales. Los recursos que obtenían de estas actividades tradicionales servían primordialmente para el autoconsumo y eran el complemento de los magros ingresos que los padres recibían del entonces Banrural Peninsular, así como de los que percibía la fuerza económicamente activa de las actividades asalariadas que, ya desde los años setenta, se vieron precisados de buscar en el medio urbano, principalmente en Mérida, ante el deterioro y abandono incontenible de la producción de los planteles de los ejidos colectivos de henequén. 
Con el paso de los años ochenta, la actividad productiva de los ejidos colectivos dedicados al monocultivo del henequén decayó definitivamente, hasta que el gobierno estatal, de común acuerdo con el gobierno federal y de conformidad con la política neoliberal asumida desde entonces por el gobierno mexicano, para los primeros años de la décadas de los noventa, decidió clausurar la agroindustria henequenera, jubilar o prejubilar de las nóminas ejidales a todos aquellos ejidatarios que habían alcanzado la edad de 60 años o que estaban por hacerlo, y liquidar a los agricultores jóvenes o maduros; quienes tan solo cumplían una jornada semanal de dos mecates $-40 \mathrm{~m}^{2}$ de actividad en los decadentes planteles ejidales y recibían un bajo estipendio por el-, pero se mantenían al tanto del cumplimiento de estas escasas labores en los planteles por necesidad de conservar su pertenencia al IMSS, que se convirtió para los ejidatarios henequeneros en la única razón de su persistencia en estas actividades y sobre todo de su relación con el Estado. ${ }^{1}$

Después del exterminio de la agroindustria henequenera y del cierre definitivo de la paraestatal Cordeleros Mexicanos, Cordemex, a manos de la entonces gobernadora interina del estado de Yucatán, para la primera mitad de los años noventa, los integrantes de las familias que habitan las 47 pequeñas comunidades rurales del municipio de Mérida, en especial sus miembros que ya se hallaban en edad económicamente activa, hombres y mujeres, prácticamente se volcaron a Mérida, a otras ciudades circunvecinas y entidades cercanas, en busca del empleo necesario que les permitiera obtener los recursos indispensables para la reproducción de sus grupos familiares.

En general, todas estas comunidades rurales meridanas están ubicadas en el centro de la región que fuera denominado «el corazón de la zona henequenera», precisamente porque en ella florecieron y se concentraron las haciendas de mayor producción del agave y adonde llegaba la materia prima para ser procesada en fibra y luego ser embalada para su trasportación por barco o ferrocarril hasta su destino, principalmente hacia Estados Unidos de Norteamérica (Villanueva 1990) y Europa. De manera que en su devenir histórico estos poblados dependieron de dicha agroindustria y de las relaciones de producción que 
imperaron en esta actividad: durante el sistema socioeconómico de la hacienda, desde mediados del siglo XIX, bajo el dominio de los hacendados; y desde 1934, cuando el gobierno cardenista decretara el fin del sistema de haciendas y la liberación de los peones, el Estado se hizo cargo de la producción a través de la creación de los ejidos colectivos y de la corporativización de los agricultores como ejidatarios, hasta que el gobierno estatal la clausurara en 1992, en el contexto del pleno impulso de la economía neoliberal en México y de las reformas estructurales que el gobierno mexicano asumió desde entonces.

Cabe señalar que 36 de estas poblaciones meridanas, las denominadas subcomisarías, tuvieron sus orígenes en las haciendas henequeneras y precisamente de ellas recibieron sus nombres actuales. De modo que la mayoría de sus habitantes son descendientes de las familias que se encontraban «acasilladas» en ellas y quienes formaban parte de las propiedades de los hacendados, cuando entonces sus miembros podían ser vendidos o trasferidos junto con las maquinarias e infraestructura.

Lo relevante para lo que venimos comentando es el hecho de que desde que la debacle henequenera se volviera incontenible o, mejor dicho, cuando el Estado la dejara sucumbir, la migración de los ejidatarios a la ciudad de Mérida en busca de empleo, para complementar los «subsidios» que el gobierno les proporcionaba bajo el concepto de jornales, se convirtió en una constante y, por lo tanto, los vínculos que los hombres y mujeres de estas comunidades comenzaron a establecer con esta ciudad también se volvieron frecuentes y estrechos por concepto de la búsqueda de empleo. Sin embargo, la integración de estos buscadores de empleo al medio urbano, desde su cabecera municipal, de ningún modo aconteció bajo su incorporación como parte de sus ciudadanos, sino únicamente como mano de obra barata que podía ser ocupada en aquellas actividades que no eran de la preferencia de los trabajadores del medio urbano, tales como la jardinería, el aseo de la ciudad, en la industria de la construcción, en las obras públicas de introducción del agua potable, el servicio doméstico, en empresas de recolección de basura domiciliaria y en otras actividades de baja remuneración. Obviamente, culturalmente fueron percibidos 
del mismo modo, como el otro, el Alter, dada su procedencia rural, su escasa preparación escolar y particularmente por ser hablante de lengua maya — sólo de las 500 encuestas aplicadas registramos que de la población de 5 y más años $48.8 \%$ declaró ser hablante de lengua maya - , aun cuando ya no vistieran la indumentaria tradicional, en especial en caso de las mujeres jóvenes o maduras, quienes paulatinamente abandonaron el uso del «hipil» de la mujer maya yucateca por la ropa occidental, como veremos más adelante.

Para finales de los años ochenta y principios de los noventa del siglo $\mathrm{XX}$, la fuerza de trabajo desocupada de las comisarías de Mérida también comenzó a dirigirse hacia las actividades que fueron surgiendo a medida que la expansión de la economía neoliberal se fue consolidando en la entidad yucateca, tales como las empresas maquiladoras de capital extranjero, por medio de las cuales el gobierno estatal intentó paliar el desempleo en la ex zona henequenera, para lo cual creó el Parque de industrias no contaminantes, con todos los servicios, carreteras, energía eléctrica, agua potable y la exención de impuestos, con el fin de hacer atractiva la oferta a los inversionistas extranjeros para que llegaran a Yucatán a instalar sus industrias maquiladoras. Se procuraría en las que se instalaran en esta región de la entidad, los inversionistas pudieran aprovechar la mano de obra desocupada y además convertirse en fuentes de empleo para los ex ejidatarios desempleados.

Asimismo, a partir de esta etapa del desarrollo neoliberal comenzaron a emerger en la entidad relaciones laborales inéditas, ya que empezaron a propagarse las modalidades de las subcontrataciones o el surgimiento de empresas intermediarias que, a final de cuentas, implicaron la contratación intermediada del trabajador con respecto al verdadero empleador y receptor directo de los beneficios del trabajador, pero que por medio de estas nuevas condiciones laborales se lograban evadir responsabilidades directas con los trabajadores, el cumplimiento de prestaciones que, en teoría, dictan las leyes federales del trabajo, pero sobre todo el pago de salarios y prestaciones justos. 
Bajo estas novedosas condiciones de relaciones laborales, lo cierto es que los vínculos económicos que la fuerza económicamente activa de estas poblaciones ha establecido con las actuales fuentes de empleo que existen en Mérida han sido sobre todo informales, de bajos ingresos, de escasa especialidad y de pocas o nulas prestaciones, que evitan por todos los medios la adquisición de antigüedad y los derechos correspondientes. En especial evitan la construcción de una conciencia de clase y la conformación de organizaciones sindicales que generen sentido de identidad laboral, la fortaleza y la conciencia de lucha por intereses comunes, como el mejoramiento de las relaciones laborales y la obtención de un salario digno capaz de satisfacer las necesidades básicas de las familias de los trabajadores; generándose de este modo una de las condiciones favorables exigidas por la política económica neoliberal y el tratado de libre comercio que es el desmantelamiento de los organismos sindicales que contribuyen a luchar - o que deberían hacerlo en teoría-, por mejores condiciones laborales de los empleados y sobre todo la intervención del Estado en la solución de los problemas del empleo o del desempleo.

Así por ejemplo, de la 500 encuestas aplicadas se obtuvo la información al respecto de que de los 827 trabajadores registrados en la muestra, 487 (58.9\%) tuvieron como destino de búsqueda de empleo la ciudad de Mérida; 304 (36.7\%) laboraban en las granjas de cerdos y aves de propiedad privada y en las industrias maquiladoras ubicadas en poblaciones circunvecinas, y 36 (4.4\%) se habían dirigido a la ciudad y Puerto de Progreso Yucatán, para desempeñarse como obreros de la construcción o meseros de los restaurantes.

Del total de los trabajadores que se dirigen a Mérida, 90\% conformado por hombres y mujeres, señaló que por lo general se desempeñan en trabajos de muy baja remuneración y escasas prestaciones, debido a su baja preparación o competencia, tales como en el servicio de limpieza y recolección de basura de la ciudad, como peones de obreros de la construcción, y en el caso de las mujeres como servicio doméstico o costureras de las industrias maquiladoras situadas en el Polígono de industrias no contaminantes, ubicado sobre las carretera que conduce a la ciudad y Puerto Progreso. Asimismo, del total de 
trabajadores registrados (827), 62\% dijo que en sus empleos no contaba con «todas las prestaciones de ley», tales como Seguro Social, derecho a utilidades, aguinaldos, préstamos, derecho a jubilación, entre otras, debido a que como ya se señaló los empleos a los que tienen acceso son de servicio doméstico, obreros de la construcción, jardineros, mozos y en las industrias maquiladoras. Al respecto, enfatizaron que si bien aquellos que se desempeñan para una empresa constructora o en las industrias maquiladoras reciben ciertas prestaciones, principalmente el Seguro Social o magros aguinaldos, por lo general estas prestaciones no logran retenerlas debido a que las empresas en la mayoría de los casos, cuando termina la construcción, los despiden, y en el caso de las maquiladoras frecuentemente «hacen reajustes de personal», cambian de razón social y despiden a sus empleados, con el fin de aprovechar los beneficios que el gobierno del estado les ofrece por generar nuevas industrias.

Otro ejemplo que podemos señalar es el de las nuevas generaciones o potenciales trabajadores que tendrán que recurrir al mercado de trabajo urbano. Así de los 960 hijos de 18 y más años, registrados en las 500 familias entrevistadas, $12 \%$ se encontraba estudiando alguna carrera técnica, mientras que $2.6 \%$ se desempeñaba en actividades agrícolas comerciales como la horticultura; $41.66 \%$ dijo que se desempeñaban en diversas empresas, como las de vigilancia privada, en fábricas de materiales de construcción, en los astilleros de barcos, en las empacadoras de pescado, en talleres de tallado de piedra cantera - en la comisaría de Dzitya-; $31.25 \%$ afirmó que trabajaba en la industria de la construcción, como peón de albañiles, y $11.97 \%$ de estos jóvenes dijo que trabajaba en el sector terciario de la economía, es decir, como servidores domésticos de residencias de la ciudad, como caballerangos de los clubes hípicos ubicados en los que fueran terrenos ejidales de las comisarías del norte de la ciudad, en el aseo urbano de ésta, en el aseo de parques y jardines o en las empresas de recolección de basura.

Es importante mencionar que, en cualquiera caso, para que la fuerza de edad económicamente activa de estas localidades pueda salir en busca de trabajo, de un modo u 
otro, el hecho es que las familias requieren indispensablemente de la reorganización y del apoyo de todos sus elementos familiares, con la finalidad de que quienes tengan posibilidades de ser empleados en el mercado de trabajo externo puedan acudir en su búsqueda y tener la seguridad de que las actividades que les corresponde realizar dentro de su núcleo familiar deberá ser realizado por alguno de los miembros que permanezca en la comunidad. Un ejemplo contundente y el de mayor frecuencia es el de las madres de familias que tienen hijas de trece o catorce años quienes asumen las responsabilidades del hogar de sus madres para permitirles salir a trabajar como lavanderas, trasteadoras y planchadoras en las casas de la ciudad de Mérida. Otro ejemplo es el de los padres, mayores de 50 años - 155 casos registrados - que aún practican el cultivo de la milpa, y que por su edad difícilmente son empleados en la ciudad, y se ven precisados de esperar el domingo para realizar aquellas actividades más complejas de este cultivo de subsistencia como la tumba del monte o la quema, precisamente cuando sus hijos asalariados no acuden a trabajar. En este sentido, la reorganización y la ayuda de todos los integrantes del núcleo familiar es de suma importancia para que los desempleados puedan salir de sus comunidades en búsqueda del trabaja necesario.

\section{ELEMENTOS SIMBÓLICOS Y DE IDENTIDAD DE LAS SOCIEDADES RURALES DE MÉRIDA}

Uno de los elementos distintivos de las comisarías y subcomisarías de Mérida lo constituye el uso extendido de la lengua maya. De acuerdo con el XII Censo de Población y Vivienda (Inegi 2000), en estas 47 poblaciones meridanas, del total de 39,255 personas, población de 5 años y más son 34,748 individuos; y 15,572 personas declaró ser hablante de lengua maya. No obstante que estos datos duros de Inegi nos reportan un porcentaje significativo de maya hablantes, en la realidad el número seguramente supera esta cantidad, ya que fueron numerosas las personas y familias que aunque en un principio nos negaron que hablaban la lengua maya posteriormente pudimos observarlas que en efecto sí la entendían y se comunicaban en esta lengua. 
Mapa 1. Mérida, comisarías y subcomisarías

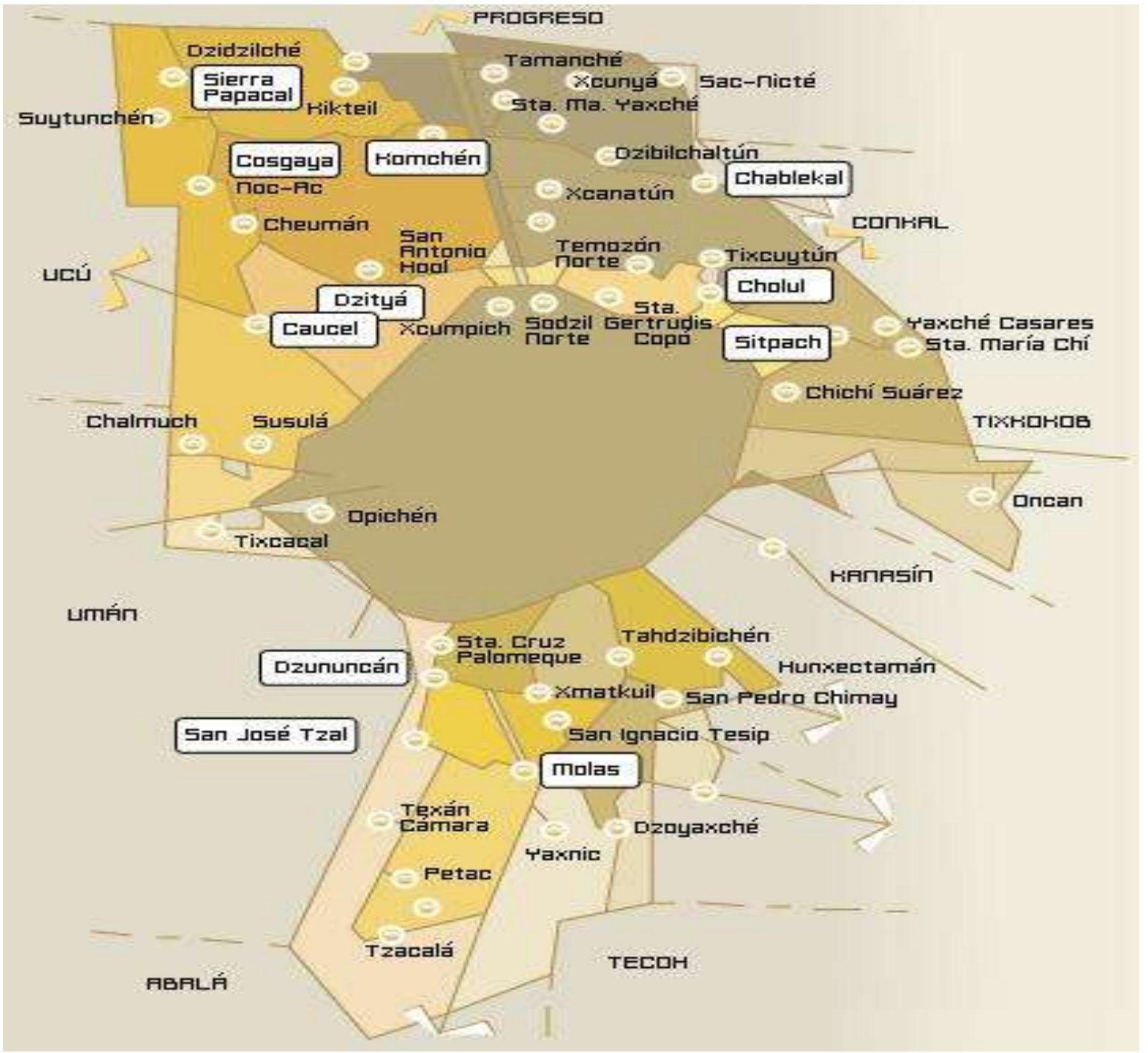

Fuente: Ayuntamiento de Mérida, 2010.

Contrariamente al uso difundido de la lengua maya, lo que sí pudimos comprobar es el avanzado abandono de la indumentaria de la mujer maya yucateca, «el hipil yucateco»; hecho que según nos explicaron las informantes que aún lo usan, ha sido por motivos del costo o el trabajo que representa confeccionarse una de estas prendas, lo cual difícilmente 
pueden hacerse o pagarse las mujeres «sobre todo que ahora hasta ellas tienen que salir a trabajar para dar de comer a sus hijos». Además, hoy día «desde que entran a la escuela les exigen a las jóvenes acudir con sus uniformes y usar la ropa deportiva que ahora para las muchachas se ha vuelto una costumbre», nos enfatizó la informante. Por esta razón, como bien señalaran estas mujeres, en la actualidad únicamente «nosotras las mujeres viejas y algunas de no de tan avanzada edad siguen usando este vestido, incluso algunas alternan el uso de la ropa occidental con el hipil, porque este es mucho más cómodo y fresco que los vestidos» (sic).

De cualquier modo, el cambio de la indumentaria tradicional en estas poblaciones es un hecho innegable no solo porque estas poblaciones y quienes por el trabajo tienen que estar en mayor contacto y dependencia con la ciudad, sino también porque en el contexto actual del trabajo o de la vida cotidiana de los habitantes, en este caso de las mujeres, en las maquiladoras o en las escuelas, como bien nos indicara la informante anterior, para las mujeres trabajadoras o estudiantes hoy es una exigencia que asistan portando el uniforme de rigor $\mathrm{y}$, por lo tanto, difícilmente pueden continuar vistiendo la ropa acostumbrada. Por su parte, en el caso de las mujeres jóvenes que «trabajan entre lugar» visten la ropa de moda sobre todo porque sus patronas las llevan a las modernas plazas comerciales climatizadas y se «sentían mal vistiendo el hipil cuando asistían a los comercios con sus patronas, sobre todo cuando se percataban que otras cuidadoras de niños vestían a la moda como sus patronas».

Además, es inobjetable que las y los jóvenes del medio rural de Mérida, como de las poblaciones de otras regiones de la entidad, al igual que los de esta ciudad capital, se hallan ya insertos al mercado no tan sólo como trabajadores sino también como consumidores de mercancías, por ejemplo de la novedosa vestimenta o los mobiliarios para el hogar que se expenden en los comercios, aparatos de sonido, refrigeradores, televisiones... En general, en la actualidad las familias del capo yucateco ya son consumidores de los nuevos estilos de vida que se difunden a través de los distintos medios de comunicación, tales como los 
teléfonos celulares y otros dispositivos que supuestamente procuran bienestar a las personas, momentos placenteros o «cierto estatus». Por lo tanto, igualmente se han convertido en participantes activos y dependientes de los efímeros dictados de la moda occidental, incluyendo el uso del ciberespacio por medio del cual se mantienen enlazados con redes sociales y nuevas amistades virtuales; lo cual consiguen a partir de sus ingresos como servidoras domésticas.

No obstante, es importante enfatizar que con los nuevos estilos de vida que las poblaciones han ido adquiriendo a partir de su mayor incorporación al empleo urbano y su dependencia hacia la ciudad, así como del abandono de ciertos elementos simbólicos de su identidad cultural, como el hipil yucateco y la negación de que aún hablan lengua maya, para las mujeres jóvenes y maduras de estas poblaciones, como para el resto de las de la entidad yucateca, aún continúa siendo para ellas un «deleite» portar el terno de gala de la «mestiza yucateca», durante las festividades de los santos patronos de sus localidades y, especial, en los bailes de las vaquerías con las que dan inicio los «festejos profanos de la fiesta del pueblo», las cuales después de muchas décadas siguen celebrando año con año.

Cabe remarcar que el terno de gala de la mujer yucateca continúa siendo uno de los símbolos de la identidad sociocultural de la mujer maya yucateca de mayor importancia, tal como lo es la lengua maya, como también lo constituye danzar al ritmo de la música jaranera, elementos simbólicos sincréticos que si bien no son totalmente originarios de la cultura maya, a través de los siglos ésta ha conseguido sintetizarlos y hacerlos suyos y de su estética particular, hasta convertirlos en parte de los símbolos representativos de su cultura con la que construyen, recrean y apuntalan su identidad, en el contexto del mundo y la cultural globalizante. Incluso, cabe enfatizar que estos símbolos de identidad de la cultura maya yucateca son también elementos de la estética de la que asimismo disfrutan, participan y se enorgullecen los ciudadanos urbanos, en especial cuando están fuera de su entidad. 
Por el contrario, en el caso de la lengua maya, los pobladores de las comisarías y sub comisarías de edad madura y adultos mayores se autodenominaron mayeros, en tanto que la gente de la ciudad que aún habla y entiende este idioma por lo regular, por ser migrantes de primera o segunda generación, niegan por todos los medios que entiendan el idioma. Por su parte las mujeres adultas mayores que portan el hipil también acertaron al definirse y ser definidas por sus paisanos o por la gente de fuera como «mestizas yucatecas»y en contraste con las «catrinas», las cuales son mujeres de la comunidad o de fuera que usan el vestido occidental, entre las cuales suelen encontrarse incluso sus hijas, hermanas, nietas o vecinas, a quienes ellas designan como tales, sin que haya carga de significado peyorativo.

Mas de ninguna manera estas mujeres o los hombres que declararon abiertamente que sí hablan maya aceptaron ser definidos como indígenas o indios por el simple hecho de vestir el hipil o de ser maya hablantes. Para ellos el concepto de indios o indígenas no es comprensible ni se justifica en la medida en que consideran que este sea el término apropiado para denominar a la gente del medio rural, como lo hacían en otras épocas los hacendados de origen español, que por tener el dominio económico y político de la entidad se sentían con el derecho de vilipendiar a sus propios trabajadores y a los desposeídos que acudían a ellos para implorarles trabajo.

Cuando pedimos a los informantes que nos explicaran las características del término indio o indígena definieron estos conceptos como aquellos atributos o comportamientos que pueden tener las personas, sean del medio rural o urbano, como intratables, déspotas, tiranos, groseros e incorregibles, sean de la clase social o del grupo social de su procedencia, con estudios o sin ellos; en este sentido, por contraposición al término indígena o indio, para ellos los valores que fundamentan la personalidad de las «personas tratables» son la expresiones de personalidades afables, honradas y solidarias, que escuchan y dialogan con cualquier individuo, independiente de su extracción social o procedencia. 


\section{RELACIONES INTERÉTNICAS DE LAS COMISARÍAS CON LOS HABITANTES DE MÉRIDA}

Bajo dicha perspectiva, los términos indígena, indio o maya con los que se ha categorizado a las sociedades rurales de Mérida, como a todas las poblaciones de la entidad yucateca, poco o nada corresponden con las propias concepciones de los informantes sobre los elementos que definen sus identidades socioculturales, ni mucho menos con los elementos que dan contenido a sus percepciones de sí mismos y de su cultura. Para ellos estos términos o conceptos sólo definen los vínculos desiguales e inequitativos que los grupos dominantes han impuesto, o que los mismos estudiosos les han etiquetado al argumentar su procedencia y sus condiciones de vida, al explicar su sujeción social, o las particularidades de sus formas de ser, de vestir, de hablar, de pensar y concebir el mundo que los rodea.

Desde la propia óptica de los informantes los conceptos indígena, indio o maya, entrañan en sí mismos una cualidad estigmatizadora a través de la cual una sociedad que se asume como «blanca», «civilizada» o «moderna», se separa o se quiere imponer simbólicamente a estos grupos socioculturales, y les hace entender y aceptar sus condiciones de subordinación, de diferencia con respecto a ellos y, sobre todo, le hace conciente de su pobreza, de su escasa preparación, de su poca competencia e imposibilidad para alternar en forma igualitaria con la gente de la ciudad, sin tomar en cuenta que estas condiciones son producto de las relaciones bajo las cuales históricamente se han reproducido estas sociedades, concepciones que incluso suelen reproducir los propios estudiosos de tales mismas sociedades y que la propia sociedad rural se ve compelida a aceptar con la finalidad de recibir los beneficios de los programas asistencialistas destinados a favorecer a los pueblos indígenas del país.

Dicho con otras palabras, por medio de estos conceptos los grupos hegemónicos han cumplido su imperiosa necesidad de distinguirse y legitimar su posición de dominio y exclusión que hacen de todos aquellos individuos o grupos sociales que consideran ajenos a ellos. Por su parte, los pueblos yucatecos de ninguna manera los aceptan y, definitivamente, los rechazan aunque sean hablantes de la lengua maya; aunque vistan hipil o tengan uno o 
los dos apellidos de linaje maya. Ayer como hoy, es prácticamente imposible escuchar de ellos una respuesta afirmativa en relación con la pertenencia a un pueblo indio, aunque ante las políticas públicas de preservación del patrimonio cultural tangible o intangible, tengan que aceptar ser definidos como pueblos indios para poder acceder a los beneficios de dichos programas de recate cultural.

Por lo general, las poblaciones de las comisarías de Mérida se autodenominan y se reconocen como sociedad mestiza o como «mayeros», en referencia a su lengua, o simplemente como yucatecos, los cuales son términos que muy poca relación o ninguna guardan con los significados de indios o indígenas e incluso con el de sociedad maya que se les atribuye desde fuera. Esta última es una categoría con la que en estos pueblos de Yucatán se denomina igualmente a la civilización que construyó los edificios arqueológicos que hoy admiramos. En este sentido, un aspecto que es importante remarcar es que para las sociedades rurales de Mérida los conceptos de «indios»o «indígenas» son conceptos que ellos entienden con los mismos contenidos construidos por el «otro» desde muchos años atrás, como: flojos, haraganes, irracionales, iletrados, atrasados, intratables, ignorantes, entre otras peculiaridades peyorativas que pueden atribuírselas tanto a sí mismos como a los «otros», cuando la persona sea cual fuere asume comportamientos que infringen las normas socialmente aceptadas.

De cualquier manera, la estrecha relación que los pobladores de las comisarías y subcomisarías mantienen con la ciudad de Mérida y sus habitantes trascurre en una continua confrontación que los hace experimentar y percibir, con mayor énfasis, su pobreza y en particular su condición estructural desventajosa, inequitativa e injusta, la cual padecen desde hace muchas décadas, con respecto a aquellos. Los hace reconocerse como parte de la sociedad meridana más pobre, abandonada, cercana y distante al mismo tiempo, porque los bienes y servicios que en la ciudad capital, su cabecera municipal, están centralizados y difícilmente se encuentran a su alcance. En especial, se sienten desprovistos del derecho al trabajo, a la educación realmente gratuita y de calidad, de igual manera desprovistos de las 
inversiones públicas para el desarrollo económico y de las condiciones de vida digna a las que toda sociedad humana aspira.

Incluso se hayan excluidos del derecho a la salud, ya que cuando se enferman deben atender sus padecimientos hasta que llegan los módulos de salud móviles a sus comunidades, que el gobierno municipal meridano les envía cada quince días, o se ven en la necesidad de vender o empeñar sus escasas pertenencias para poder asistir al médico particular y comprarse los medicamentos con los cuales puedan restablecer la salud de sus enfermos. Además, es importante mencionar que el hecho de que algunas poblaciones cuenten con clínicas de campo del Seguro Social no es garantía de que reciban una atención adecuada cuando se enfermen ni la seguridad de que les suministren los medicamentos requeridos, como el gobierno propaga y se hace propaganda por los diversos medios de comunicación, ya que por lo general estas clínicas de primer nivel carecen de los aparatos y personal necesario, así como de los medicamentos más indispensables, por lo que por lo general los enfermos se ven precisados de recurrir a los médicos particulares y surtir las recetas con sus propios recursos, con el consiguiente perjuicio para sus precarias economías.

Acudir a Mérida, su cabecera municipal, significa para ellos adentrarse desde temprana hora a un mundo prácticamente ajeno en donde deben dispersarse hacia todas direcciones en busca del empleo ansiado o para satisfacer cualquier cantidad de necesidades que en sus poblaciones no hallan. En muchos casos el encuentro de los buscadores de trabajo con el medio urbano suele ser hasta violento, como en el caso de las numerosas mujeres de la tercera edad o de las jóvenes madres solteras e incluso de las ya casadas, quienes llegan todos los fines de semana para establecerse en las transitadas avenidas de la ciudad para pedir limosna a los conductores; o como en el caso de los jóvenes que han comenzado a proliferar por los distintos rumbos de la ciudad para limpiar los cristales de automóviles a cambio de unas monedas y en no pocas ocasiones de agresiones y reclamos por la osadía de 
iniciar la limpieza de los parabrisas de los automóviles sin el consentimiento de los conductores.

Pero esta confrontación no solo sucede en un sentido, es decir, por los efectos causados por el traslado de los habitantes del medio rural a su cabecera municipal. También la ciudad y sus habitantes se han adentrado y le han ganado terrenos a estas poblaciones, tal como ha sucedido en las subcomisarías conurbadas de Xcumpich, Dzodzil Norte, Temozón, Santa Gertrudis Copo, Santa María Chí, Xacanatún Dzytiá, y el ex pueblo y hoy colonia de Chuburná de Hidalgo, entre otras localidades, hacia donde, por lo menos desde hace dos décadas se ha extendido la mancha urbana; en las que numerosas empresas constructoras adquirieron terrenos del antiguo ejido de los pueblos para edificar grandes centros comerciales y fraccionamientos residenciales. Pero estas poblaciones meridanas también se han visto sujetas a expropiaciones de sus tierras que hasta antes de las reformas al artículo 27 constitucional eran intocables e inalienables, ya que el gobierno estatal hizo numerosas ex propiaciones con la finalidad de instalar en esos terrenos el parque de industrias no contaminantes, para las maquiladoras de capital extranjero, a las que les ofreció toda la infraestructura indispensable.

En la actualidad, los moradores de las nuevas viviendas de los fraccionamientos para familias de poder adquisitivo alto y medio, construidas en los que fueran los terrenos ejidales de estas subcomisarías, han influido en la trasformación de las costumbres de los habitantes originales, como por ejemplo en el abandono de la cría de animales de traspatio, en la quema de las hojas secas y de la basura orgánica en los solares, «porque contaminan el ambiente con malos olores» y ocasionan molestias a los nuevos avecindados. Incluso se han visto afectados en la producción de su agricultura de subsistencia porque hoy día los pocos ex campesinos que aún practican la milpa en pequeña escala, deben responder a los periodos establecidos por la dependencia del ramo con la finalidad de no propiciar incendios, durante el periodo de seca, y sobre todo para evitar que el humo de la quema del monte invada la ciudad y moleste a los nuevos habitantes ubicados en los fraccionamientos 
construidos en los terrenos de las comisarías, comprados a los ex ejidatarios por las industrias constructoras y los empresarios de inmobiliarias, después de las reformas al artículo 27 constitucional.

Del mismo modo, las comisarías absorbidas por la ciudad se han visto afectadas en sus festividades patronales por la presencia de los nuevos habitantes, quienes son ajenos a estas comunidades y a sus representaciones simbólicas. Para éstos, las procesiones de los gremios, los cohetes, las corridas de toros, son únicamente actividades que además que ocasionan que la gente beba alcohol, provocan embotellamientos vehiculares, «ruido»y «mucho temor» entre los nuevos habitantes, en especial en el momento de las corridas de toros. Aunque también los pobladores originales tienen nuevas percepciones con respecto a sus «nuevos vecinos», cuyas viviendas en la mayoría de los casos están separadas de las humildes viviendas por altas murallas, pero en estos casos los sentimientos son de una toma de conciencia sobre la pobreza en que viven, de impotencia por no tener los bienes y servicios que tienen los nuevos espacios habitacionales, los cuales ni remotamente pueden adquirir o consumir; en no pocos casos las mujeres terminan por ser servidoras de esas viviendas adonde sólo pueden acceder registrando su entrada y salida con el vigilante. Esta es la misma percepción que experimentan en relación con la presidencia de su cabecera municipal, en donde incluyendo a sus autoridades locales son tratados como sociedades que deben ser apoyadas para que sobrelleven la pobreza extrema, o no, en que se encuentren.

De hecho, según nos señalaron los regidores de estas poblaciones, las relaciones que establecen con el presidente(a) municipal de Mérida se da a través de los diferentes programas asistencialistas por medio de los cuales el gobierno meridano intenta contribuir a paliar la pobreza de estas sociedades por medio de poner en marcha ciertos programas, tales como la cría de aves, la impartición de talleres de capacitación en diversos oficios y el otorgamiento de las becas de Oportunidades para los estudiantes que el gobierno federal puso en marcha, programas asistencialistas que son percibidos por estas sociedades como dádivas del gobierno, como «migajas» que les dejan, después de servirse de los cuantiosos 
recursos que se destinan a estos programas de combate a la pobreza para las comunidades mayas o indígenas de la entidad que viven en un nivel de «pobreza» o «pobreza extrema», de caridades que a final de cuentas las necesitan para complementar los recursos que logran conseguir a través de los trabajos que desempeñan los integrantes de las familias.

Al respecto, las informantes acertaron decir que sabían perfectamente que «con un paquete de 24 pollitos y dos costales de alimento balanceado» que les proporcionan de ningún modo servirían para el «mejoramiento de la economía familiar», porque con ese número de animalitos difícilmente podían convertirse en granjeros ni mucho menos podrán superar los problemas económicos o de alimentación de sus familias. Sin embargo, por una parte, apreciaban el poder contar con esas aves y disfrutaban el hecho de poder alimentarlas y verlas crecer aunque, por otra parte, aceptan estas subvenciones del gobierno porque las necesitan y, además, porque tienen la plena conciencia de que los recursos repartidos «son parte de los impuestos que cobran a la sociedad», que todos los meridanos tienen que pagar, o de las partidas presupuestales que el gobierno estatal solicita al federal en nombre de las sociedades pobres y marginadas, con el fin supuesto de atenderlas, de paliar las necesidades de los ciudadanos de segunda; los cuales únicamente cobran importancia y valor en tiempos de elecciones, para luego ser de nuevo olvidados y obviados por los grupos políticos en contienda.

Ante la actual política para el «desarrollo de los pueblos indios»y sus necesidades apremiantes de recursos, los habitantes de las poblaciones rurales de Mérida, como parte de sus estrategias de supervivencia, se han visto precisados de aceptar la identidad indígena, misma que ellos siempre han negado tener, con el fin de acceder a los apoyos promovidos por medio de las organizaciones gubernamentales y no gubernamentales, que se han conformado e institucionalizado no solo con el afán de contribuir al «desarrollo» de estos pueblos, también de procurarles una participación más equitativa en la redistribución de los recursos públicos, y como fuentes de trabajo para los lideres o profesionistas que ven en la creación de estas organizaciones la oportunidad de tener la ocupación que ellos mismos no 
hallan en el mercado laboral neoliberal, cuando concluyen sus estudios profesionales y se enfrentan a la problemática del desempleo predominante.

Así, por ejemplo, ante las expropiaciones de terrenos ejidales que el gobierno estatal ha realizado en estos poblados para propiciar el crecimiento urbano o ante el acoso que estas comunidades comenzaron a experimentar de los especuladores de sus tierras ejidales, desde que se promulgaran y se aceptaran los cambios al artículo 27 constitucional y la Ley Agraria, el manejo de la identidad indígena se ha convertido en un recurso al que los ejidatarios yucatecos han tenido que recurrir, con el fin de solicitar el apoyo de las organizaciones que se ocupan de la defensa de los derechos de los pueblos indígenas, para impedir que sean despojados de sus únicas propiedades que les fueron concedidas durante la reforma agraria cardenista.

En este sentido, se puede señalar que han aprendido a utilizar o a manejar una identidad que no sienten suya, que siempre han percibido como fundamento de su exclusión o marginación socioeconómica y cultural, pero que en el contexto de su interacción política y social con el Estado y en el marco de la economía neoliberal, ahora la aceptación de la categoría como sociedades indígenas, les posibilita obtener recursos y luchar por la defensa de sus tierras. Un ejemplo de estos actos sucedió recientemente en la comisaría de Sierra Papacal, ${ }^{2}$ en el que los ejidatarios se vieron precisados de denunciar a la prensa el peligro de ser despojados de una vasta extensión de terrenos por pare de «un señor que llevaba consigo uno libro grandote», quien los hostigaba y bajo amenazas exigía a los ejidatarios para que firmen la cesión de sus terrenos para un «político influyente» y que de no hacerlo «les iría muy mal». El objetivo se trataba de amplios terrenos que se hallaban ubicados en la vera de una amplia carretera recién construida y que conducía hacia el parque científico, que el gobierno del estado tenía programado construir en terrenos expropiados a la misma comisaría; hasta el momento los ejidatarios propietarios se encuentran en litigio y luchando para que el personaje influyente no logre sus objetivos (Diario de Yucatán, sección local, 2011: 11). 


\section{CONCLUSIONES}

En Mérida no solo habitan pobladores originarios o familias procedentes de los municipios del estado, que en el trascurso de los años se han visto confinados a migrar por la crisis de la agricultura, el desempleo en sus comunidades y la falta de políticas públicas para incentivar la producción en el campo yucateco. En las últimas décadas el crecimiento de esta ciudad capital ha acontecido también por la migración de familias e individuos procedentes de otras entidades del país, así como de otros países que llegan en busca del empleo que no encuentran en sus lugares de origen. Como en el caso de las numerosas etnias de chiapanecos y centroamericanos que han logrado establecer sus tiendas de artículos artesanales o dedicarse al comercio informal vendiendo sus productos. Asimismo, no debemos dejar de mencionar a los numerosos extranjeros que llegan en busca de la relativa «tranquilidad»y «seguridad» de la vida provinciana, como lo representa el caso de numerosas familias estadounidenses o canadienses, principalmente, quienes están adquiriendo y reconstruyendo las casonas del centro de la ciudad o los predios ubicados en la zona veraniega de la costa para quedarse o pasar aquí las temporadas invernales de sus países.

De cualquier manera es necesario recordar que las migraciones al estado de Yucatán no han sido recientes, sino que los desplazamientos demográficos han tenido lugar desde hace muchas décadas, aunque ahora han cobrado mayor importancia. No debemos olvidar que en el Yucatán de finales del siglo XIX, ante la bonanza económica generada por la agroindustria henequenera, también acontecieron numerosas migraciones de coreanos, libaneses, alemanes y de otros grupos étnicos del país, como los yaquis, quienes fueron traídos en forma forzosa a tierras yucatecas para trabajar en las haciendas henequeneras.

En este sentido, se puede afirmar que la cultura maya yucateca se ha nutrido de múltiples cosmovisiones, percepciones y símbolos de otras culturas, y que en el correr de las décadas ha devenido en una síntesis de elementos culturales propios con los de otras culturas con las 
que ha establecido contacto, al mismo tiempo que los valores culturales originarios son apropiados por las sociedades avecindadas en suelos yucatecos. Por esta razón, la sociedad yucateca contemporánea representa un complejo cultural dinámico, rico en símbolos y expresiones que sirven de base para la construcción y recreación de una identidad fortalecida, en continuo movimiento, que le han permitido su reproducción y su persistencia dentro del marco de la sociedad más amplia y de los procesos que en ella tienen lugar, incluyendo los que proceden de las relaciones del mercado y la cultura globales.

Por último, cabe destacar que de acuerdo con los objetivos de la globalización económica y cultural, en el contexto de sus procesos de capitales y relaciones trasnacionales de mercado, de las competitividades y los arreglos comerciales y políticos entre los gobiernos de las naciones con las que nuestro país firmó el Tratado de Libre Comercio, quienes han resultado ser los más beneficiados han sido las clases pudientes económica y políticamente. A las clases campesinas, como a las demás clases trabajadoras de la entidad, de la región y del país en general, este neoliberalismo solamente les ha concedido la propiedad de sus tierras - en el caso de los campesinos - y la libertad de venderlas junto con su fuerza de trabajo, asediados por el desempleo y el hambre.

En el caso de la tierra del campesinado yucateco este proceso neoliberal global, a escala local fue formalizado a partir de las reformas al artículo 27 constitucional, por medio de las cuales el Estado impulsó la parcelación del ejido y abrió los candados que impedían la compra, arrendamiento o asociación de los ejidatarios con agentes ajenos a sus comunidades. Lo más significativo de la actual reforma estructural del Estado mexicano es que por medio de ella este logró liberarse del compromiso contraído y escasamente cumplido con los sectores campesinos del país al concluir la Revolución mexicana de la primera década del siglo XX, sobre todo cuando tuvo lugar la reforma agraria cardenista y el Estado aún conservaba su característica social posrevolucionaria, que se vio confinado a abandonar por presiones de los gobiernos poderosos con los que firmó el Tratado de Libre Comercio. 
Desde entonces, este proceso neoliberal ha generado mayor dependencia económica y cultural de la sociedad mexicana y de sus poblaciones rurales hacia el mercado capitalista y la cultura global, ya sea como productores, en algunos casos, o como prestadores de mano de obra barata y consumidores, quienes hoy día de todas maneras tienen que seguir planteándose estrategias para sobrevivir en el contexto predominante de la economía global, que ha vuelto más flexible el empleo, o mejor dicho inseguro, volátil y de baja remuneración, provocando de este modo que el único efecto contundente del proceso económico neoliberal sea sobre todo la profundización de la pobreza y el aumento del número de pobres y, por otro lado, la centralización de la riqueza en manos de un reducido sector social de la clase pudiente.

De cualquier modo, no obstante a los impactos que ha introducido la globalización económica y cultural en los pueblos mayas, estos continúan siendo parte importante y significativa de nuestra sociedad yucateca, tanto en lo referente a número como en presencia y representaciones culturales. Los impactos de los cambios globales en el ámbito local no han conseguido impedir que las poblaciones rurales de la entidad yucateca sigan siendo portadoras de numerosas expresiones simbólicas: formas de ser, de actuar, de sentir y pensar, de concebir sus creencias y prácticas y de recrear sus elementos simbólicos trascendentales a partir de los cuales, históricamente, han configurado y trasmitido los valores que dan fundamento a su cosmovisión de sí mismo, de la sociedad, de la vida, de la naturaleza y del orden que las cosas tienen en el universo en el que ellos mismos se incluyen.

Así, en tanto se cristaliza la transición hacia mejores condiciones de vida, hasta ahora inciertas y difusas en el contexto del modelo económico neoliberal, que la globalización y la modernización prometen a las naciones que cayeron en la fascinación de sus encantos, los pueblos yucatecos han demostrado la fortaleza para adaptarse y sobrevivir en este contexto y, lo más importante, sin perder los elementos simbólicos que definen su sentido 
de identidad con su cultura particular, sin diluirse en la uniformidad y en el infinito del desarrollismo económico; sin rechazar su participación de las novedades globales como el uso del teléfono celular, del ciberespacio y de la moda de vanguardia que se expende en los aparadores del mercado. Como vimos a través de estas líneas, un indicador de esta continuidad lo representa la vigencia del uso de la lengua maya y de otras expresiones simbólicas, como las festividades a los santos patronos, a los guardianes celestiales de la naturaleza; aunque en algunos casos se hallan visto precisados de resignificar sus representaciones, como hacer su ofrendas en la iglesias de sus comunidades o de pagar misas por ganarse o propiciarse el bienestar celestial: lo relevante es que siguen manteniendo la esencia de los elementos simbólicos de su cultura.

En síntesis, los meridanos rurales además de que han conseguido preservar numerosos elementos simbólicos de su cultura y de su identidad, como «mestizos yucateco» o «mayaros», han logrado adaptarse a las nuevas condiciones laborales que les imponen los nuevos tiempos económicos del mercado neoliberal, ya que es innegable que aun con su baja competitividad siguen participando en la economía local a través de seguir realizando las actividades que la gente de la ciudad no desea realizar pero son indispensables que se lleven a cabo, como el aseo urbano, la recolección de basura, el servicio doméstico, o las actividades de nueva era, por ejemplo vigilantes de empresas privadas, trabajadores de las maquiladoras, entre otras actividades. Por lo tanto, siguen teniendo una importante participación en actuales procesos de desarrollo económico de su cabecera municipal, aunque sea esencialmente como mano de obra poco calificada. 


\section{BIBLIOGRAFÍA}

Aguado, José y Portal María A., 1992, «Identidad, ideología y ritual», Texto y Contexto n. 9, Universidad Autónoma Metropolitana, UI, México.

Aguirre Beltrán, G., 1992, El proceso de aculturación y el cambio sociocultural, Obra Antropológica, Tomo VI, Universidad Veracruzana, Instituto Nacional Indigenista, Gobierno del estado de Veracruz, Fondo de Cultura Económica, México.

Ajens, Andrés, 1997, «De las identidades a las industrias culturales (ida y vuelta). En torno a las dimensiones culturales del desarrollo», Revista de identidades, interculturalidad: políticas culturales de alcance regional, n. 19, Instituto Andino de Artes Populares, IADAP, Quito, Ecuador, pp. 47-65.

Audefroy, Joel, 2004, «Estrategias de apropiación del Espacio por los indígenas en el centro de la ciudad de México», en Ciudad, pueblos indígenas y etnicidad, Yanes, Pablo, Virginia Molina y Óscar González, Colección: La ciudad, México, Universidad de la Ciudad de México, Gobierno del Distrito Federal, México, pp. 249-286.

Ayuntamiento de Mérida [Yucatán], 2010, «Mapa del municipio de Mérida y sus comisarías y sub-comisarías», en http://www.merida.gob.mx/comisarias/mapa.htm [consulta: 3 de octubre de 2010].

Bartolomé, Miguel A., 1997, Gente de costumbre y gente de razón: las identidades étnicas en México, INI, Siglo XXI, México.

Bitrán, Yael, 2001, México: historia y alteridad: perspectivas multidisciplinarias sobre la cuestión indígena, Universidad Iberoamericana, Departamento de Historia, México. 
Bracamonte y Sosa, Pedro, 2005, «Los solares urbanos de Mérida y la propiedad territorial indígena en el Yucatán colonial», en Urbi indiano. La larga marcha a la ciudad diversa, coordinado por Pablo Yanes, Virginia Molina y Óscar González, Colección: La ciudad, Universidad de la Ciudad de México, Gobierno del Distrito Federal, Secretaría de Desarrollo Social, México, pp. 129-142.

Castellanos Guerrero, Alicia, 2005, «Exclusión étnica en las ciudades del centro y sureste», en Urbi indiano. La larga marcha a la ciudad diversa, coordinado por Pablo Yanes, Virginia Molina y Óscar González, Colección: La ciudad, Universidad de la Ciudad de México, Gobierno del Distrito Federal, Secretaría de Desarrollo Social, México, pp. $145-167$

Diario de Yucatán, Sección local, domingo 24 de julio de 2011, México, p. 11.

Giménez, Gilberto, 1994, «Comunidades primordiales y modernización en México», en Modernización e identidades sociales, coordinado por Gilberto Giménez y Ricardo Pozas H., Colección: Pensamiento social, Instituto de Investigaciones Sociales, UNAM, Instituto Francés de América Latina, México, pp. 151-183.

Instituto Nacional de Estadística, Geografía e Informática, INEGI, 2000, XII Censo de Población y Vivienda, INEGI, México.

Pacheco Castro, Jorge, 1992, «La reestructuración henequenera de los 90: ¿Una política agrícola de Campesinización?», en Campesinos y sociedad, coordinado por Othón Baños Ramírez, Othón, Mérida, Yucatán, UADY, México, pp. 223-254.

2005, «El cambio sociocultural desde la óptica de algunas teorías antropológicas», en Análisis del cambio sociocultural, editado por Rosario Esteinou y Magdalena Barros, Publicaciones de la Casa Chata, CIESAS, México, pp. 43-69. 
Pinkus Rendón, Manuel, 1993, «Campesinos yucatecos de Yaxché y alternativas de supervivencia con el Programa de Desarrollo de la Zona Henequenera», Tesis de licenciatura en Sociología, Instituto de Ciencias Sociales de Mérida, A. C., México.

Villanueva Mukul, Eric, 1990, El henequén en Yucatán. Industria, mercado y campesinos, Maldonado Editores, CULTUR, INAH, Centro Regional de Yucatán, CEDRAC, México.

Wolf, Mauro, 1987, La investigación de la comunicación de masas: Crítica y perspectivas, Paidós, Barcelona.

\section{Notas}

\footnotetext{
${ }^{1}$ De hecho, la dependencia de estas sociedades campesinas con respecto a la industria henequenera comenzó a dejar de ser tal desde mediados de la década de los setenta, cuando la aparición de las fibras sintéticas derivadas del petróleo en el mercado internacional hizo que se contrajera la demanda del mercado para las fibras de origen natural y, entonces, el gobierno optó por reducir, paulatinamente, la creación de nuevas áreas de cultivo. A partir de estos acontecimientos en la comercialización de la fibra de henequén y de la reducción de las inversiones públicas para la regeneración de los planteles en decadencia, al mismo tiempo, los campesinos comenzaron a perder sus áreas de ocupación hasta el grado de tener que ser subsidiados por el gobierno y sostenidos con una jornada de trabajo semanal de dos mecates de cultivo; como pago recibían una eximia cantidad de dinero del Banco de Crédito Rural Peninsular, Banrural, el cual era otorgado por esta dependencia bajo el concepto de jornales subsidiados a fondo perdido (Pacheco 1992: 224, Pinkus 1993: 2930).

${ }^{2}$ Comisaría meridana ubicada al norte de la ciudad y muy cercana a la costa yucateca.
}

Fecha de recepción: 15 de marzo de 2011.

Fecha de aceptación: 9 de agosto de 2011. 